\title{
A Review of Hypodontia: Classification, Prevalence, Etiology, Associated Anomalies, Clinical Implications and Treatment Options
}

\author{
Ibrahim AIShahrani, Rafi A Togoo, Mohammed Ali AIQarni
}

\begin{abstract}
A retrospective review of literature was carried out to determine the classification, prevalence, etiology, associated anomalies, clinical implications and treatment options for hypodontia. Many methods of classification have been reported in the literature. Some researchers have classified hypodontia as isolated family form or as an inherited form; others have defined the congenital absence of teeth according to the number of missing teeth and yet classified hypodontia according to the severity of the condition. The prevalence of hypodontia in the primary dentition is found to be very low whereas the occurrence of tooth agenesis varies in the permanent dentition based on ethnic and sex differences. The tooth most commonly found to be missing is the third molar. With regard to the remaining 28 teeth, metaanalysis has revealed that the teeth most commonly affected are the mandibular second premolars, maxillary lateral incisors, maxillary second premolars and the mandibular incisors. From the literature it is evident that the etiology of hypodontia is varied and that genetic, epigenetic and environmental factors may be contributory factors. Tooth anomalies reported in the literature to be associated with hypodontia, include microdontia, canine impaction, taurodontism, transposition and rotation of teeth, and hypoplastic alveolar bone. Researchers have suggested that clinical management of hypodontia requires careful multidisciplinary planning and has financial implications. The suggested members of the team should include general dental practitioners, dental nurses, orthodontists, pediatric dentists, prosthodontists, oral and maxillofacial surgeons, specialist laboratory technicians, clinical psychologists, clinical geneticists, dermatologists, speech and language therapists.
\end{abstract}

Keywords: Hypodontia, Classification, Etiology, Associated anomalies, Management.

How to cite this article: AIShahrani I, Togoo RA, AIQarni MA. A Review of Hypodontia: Classification, Prevalence, Etiology, Associated Anomalies, Clinical Implications and Treatment Options. World J Dent 2013;4(2):117-125.

Source of support: Nil

Conflict of interest: None declared

\section{INTRODUCTION}

Hypodontia is generally defined as the developmental absence of one or more teeth, excluding the third molars, either in primary or permanent dentition. Researchers have used a variety of terminology to describe the condition, such as a reduction in teeth number, teeth aplasia, congenitally missing teeth, absence of teeth, agenesis of teeth and lack of teeth. ${ }^{1-11}$ The missing teeth are those which have failed to erupt clinically in the oral cavity and even in radiographs there is no sign of the teeth starting to appear; the cause is usually disturbance during the early stages of tooth development. ${ }^{3,12}$ Hypodontia is one of the most common human dental developmental anomalies. 2,3,7,8,12-15

\section{CLASSIFICATION}

Many methods of classification have been reported in the literature. ${ }^{2,5,7,8,12-14,16-23}$ Some researchers have found the congenital absence of teeth to occur either as an isolated family form or as an inherited form. The inherited form could be either autosomal-dominant, autosomal-recessive or an X-linked trait. ${ }^{20}$ Others have defined the congenital absence of teeth according to the number of missing teeth. ${ }^{8,14,17,21,23-25}$ Hypodontia refers to the condition where there is an absence of fewer than six teeth. The term oligodontia is usually used to describe a larger number of missing teeth (six or more). Anodontia is the complete absence of teeth.

Dhanrajani ${ }^{5}$ classified hypodontia according to the severity of the condition following the method of previous researchers. ${ }^{13,26}$ He used 'mild to moderate hypodontia' to denote agenesis of two to five teeth, and referred to the absence of six or more teeth, excluding the third molars, as 'severe hypodontia'. 'Oligodontia' is the absence of multiple teeth, usually associated with systemic disorders. ${ }^{5}$ Many other researchers have used similar methods of classifying the congenital absence of teeth. ${ }^{19,27}$ In general, they identify three categories of hypodontia, excluding third molars, as follows:

- Mild with 1 or 2 missing teeth

- Moderate with 3-5 missing teeth

- Severe with 6 or more missing teeth

Hypodontia is also classified as either isolated hypodontia or syndromic hypodontia. Isolated hypodontia refers to those cases without syndrome. ${ }^{28,29}$ Thus, hypodontia can occur either as part of a syndrome or as a nonsyndromic, familial form; in the latter it occurs as an isolated trait, affects variable numbers of teeth and appears either sporadically or as an inherited condition within a family pedigree. ${ }^{23,29}$ 


\section{PREVALENCE}

\section{Primary Dentition}

The prevalence of hypodontia in the primary dentition is found to be very low. The range has generally been between 0.1 and $0.9 \%$ of the population. ${ }^{2,8,30}$ The chance of having the permanent successors missing is, by contrast, very high. ${ }^{8,31}$ In a study involving a sample of Saudi children, the teeth found to be missing most frequently in the primary dentition were the upper and lower lateral incisor. ${ }^{31}$ Larmour et $\mathrm{al}^{32}$ reviewed many previous studies and found that the prevalence of hypodontia in deciduous dentition was between $0.5 \%$ in the Icelandic population and $2.4 \%$ in the Japanese population.

\section{Permanent Dentition}

The occurrence of tooth agenesis varies in the permanent dentition. Polder et $\mathrm{al}^{22}$ used meta-analysis and found that the prevalence of missing permanent teeth varies from 2.2 to $10.1 \%$, excluding third molars, which are absent in around $20 \%$ of individuals in the recorded population. The highest prevalence was found in Australian Caucasians, with 6.3\%, followed by European Caucasians (5.5\%) and then North American Caucasians (3.9\%). Polder et $\mathrm{al}^{22}$ also showed the prevalence in African Americans (3.8\%), Saudi Arabs (2.5\%) and Chinese (6.9\%) but they did not include these in their meta-analysis, since according to them the samples used in studies of these populations were too small. Another review has shown that the prevalence of hypodontia apart from the third molars varied between 2.6\% in Saudi Arabia and $11.3 \%$ in Ireland, while in the United Kingdom it was found to be between 4 and 4.5\%. ${ }^{32,33}$ The authors suggest that these variations in prevalence may result from (a) the different age groups in the samples, since in younger groups there might be some teeth which are still to erupt, whereas in older patients teeth might have been extracted, (b) differences in sampling methodology, (c) racial differences and (d) differences in the diagnostic criteria employed. ${ }^{32,33}$ In a study conducted in 1974, it was found that the prevalence rate in British children was 3.5 to $6.5 \%$ in the permanent dentition, excluding third molars. ${ }^{2}$

Variations have been found in the prevalence of hypodontia between different ethnic groups; in some African and in indigenous Australian populations the prevalence was found to be $1 \%$, but it could be as high as $30 \%$ in Japanese populations. ${ }^{34}$ In African Americans, it has been estimated to be $7.7 \% .^{3}$ Also, in Scandinavian children, the prevalence of agenesis in the permanent dentition is reported to be 6 to $8 \% .^{35}$ In the American population, hypodontia is more common in whites than in blacks, and the number of missing teeth is also higher in whites than in blacks. ${ }^{36}$ In the Indian population the prevalence of hypodontia has recently been found to be $4.19 \%{ }^{37}$ The prevalence of tooth agenesis in the Turkish orthodontic population has been found to be $4.6 \%,{ }^{38}$ and $6.4 \%$ in the Brazilian orthodontic population; ${ }^{39}$ by contrast, in Thai populations it is as high as $26.1 \% .{ }^{40}$

It is clear from all the studies mentioned above that the prevalence of missing teeth varies among different populations. These differences found in prevalence may not be true ethnic differences, however, but could be the result of variations in sampling methodology, data collection methods and participants' ages. ${ }^{8}$

A possible relationship between tooth agenesis and sex has also been investigated. There have been studies which have found higher incidences of tooth agenesis in females. ${ }^{2,14,22,41}$ Polder's ${ }^{22}$ meta-analysis found a male to female ratio of 1:1.4. Brook ${ }^{2}$ summarized the findings of numerous studies which evaluated the effect of sex on hypodontia in the permanent dentition, and concluded that hypodontia is less common in males than in females, the ratio being 1:1.5. Recently, Mattheeuws ${ }^{41}$ reviewed 19 papers from a total of 42 studies on the subject and reported that girls tended to have a slightly higher occurrence of missing teeth than boys of the same age. Another review showed that occurrence was higher in females than in males, with a ratio of 3:2. ${ }^{32}$ In American white children, it was found that more girls (63\%) had hypodontia than boys $(37 \%),{ }^{42}$ while among the Irish population the ratio of girls to boys with hypodontia was $1.3: 1 .^{43}$

\section{DISTRIBUTION OF HYPODONTIA TEETH}

The tooth most commonly found to be missing is the third molar. Lynham ${ }^{44}$ found the third molar to be missing in onefifth of the Australian population. With regard to the remaining 28 teeth, meta-analysis has revealed that the teeth most commonly affected are the mandibular second premolars (41\%), maxillary lateral incisors (23\%), maxillary second premolars (21\%), and the mandibular incisors (6\%). ${ }^{22}$ In the Australian population, apart from the third molars, the most commonly affected teeth have been found to be the second premolars and upper lateral incisors. ${ }^{1,16}$ In African Americans, it is the mandibular second premolars which have been found to be missing most frequently, ${ }^{3}$ while among the Japanese the most frequently missing tooth was the mandibular second premolar (23.7\%), followed by the maxillary second premolar (21.5\%), maxillary lateral incisor (17.2\%) and mandibular first incisor (14.0\%). ${ }^{45}$ The same pattern has recently been reported in the Irish population, ${ }^{43}$ whereas in American white children the most commonly 
missing teeth apart from the third molars were the second premolars (50\%), lateral incisors (23\%) and maxillary second premolars (15\%). ${ }^{42}$ Davis $^{46}$ found that in Asian populations the mandibular lateral incisors were the most affected. By contrast, in all United Kingdom studies the most frequently affected teeth are the mandibular second premolars, while in all Caucasian studies the mandibular second premolars and the maxillary lateral incisors are the teeth most commonly found to be missing. Some researchers have found the maxillary permanent canine to be missing but the instances of this are very rare. ${ }^{32}$ Hypodontia of the maxillary central incisors, canines or first permanent molars is rare, occurring principally in cases of severe hypodontia. ${ }^{13}$

The most common congenitally absent teeth in the European population are the third molars, followed by the mandibular second premolars, the maxillary lateral incisors and lastly the maxillary second premolars. ${ }^{47,48}$ It has been found that 9 to 37\% of different populations have the third molars missing. ${ }^{49}$ It has been proposed that if the third molars were congenitally absent then the probability of having other missing teeth is 13 times greater. ${ }^{36,50}$ The prevalence of missing mandibular second premolars is around $2.8 \%$, while maxillary lateral incisor agenesis is in the range of 1 to $1.6 \%{ }^{49}$ There appears to be a degree of symmetry in the absence of all teeth except the maxillary lateral incisors, where the absence of the left lateral was more common than the right. ${ }^{50}$ In a review article it has been suggested that symmetrical hypodontia is predominant. ${ }^{33}$ Unilateral missing teeth are more common than bilateral teeth, although not in the upper lateral incisors. ${ }^{22}$ However, Hashem et al ${ }^{43}$ found no evidence of symmetry of missing teeth between the right and left sides among the Irish population. Another group of researchers have revealed that congenital absence commonly affects just one tooth of a pair, not both, which means that hypodontia occurs unilaterally. They have also found no suggestion in these data of directional asymmetry. ${ }^{42}$ However, among the Chinese population a different pattern has been found, the most commonly affected teeth being the lower incisors, followed by the upper second premolars and then the upper lateral incisors. ${ }^{46}$ All the review studies have shown that mild hypodontia is the most common, affecting $80 \%$ of those who have the condition. ${ }^{7,22,32,36}$

Recently, a study presented a pattern for the missing teeth in nonsyndromic severe hypodontia, using a published method called the 'tooth agenesis code' (TAC) procedure. ${ }^{51}$ The TAC procedure is based on the formula $2^{(\mathrm{n}-1)}$, in which $\mathrm{n}=$ tooth number. For example, the tooth value for the first premolar (tooth 4 ) is $2^{(3)}=8$. The TAC is the sum of the tooth values. If two teeth were missing in the upper right quadrant (e.g. two premolars), the TAC value for that quadrant would be $2^{(3)}+2^{(4)}=24$. Van Wijk and $\operatorname{Tan}^{52}$ reported that the common patterns in the upper arch are agenesis of the lateral incisors and of both premolars, with a percentage of $13 \%$, and in the lower arch the pattern is agenesis of all mandibular molars, with a percentage of $11.5 \% .^{29}$

\section{ETIOLOGY}

From the literature it is evident that the etiology of hypodontia is varied and that genetic, epigenetic and

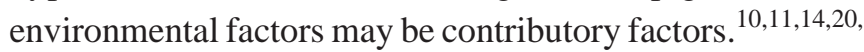
26,33,52-55 As with other conditions, the causes of missing teeth can be classified into general and local. The general category includes cases where there is a genetic cause, particularly syndromes such as Down syndrome, cleft lip and palate and ectodermal dysplasia. Local factors that result in hypodontia include early irradiation of tooth germs, hormonal and metabolic influences, trauma, osteomyelitis and unintended removal of a tooth germ during the extraction of a primary tooth. ${ }^{21}$ Many researchers have suggested models and concepts of tooth agenesis. ${ }^{26,56-61}$ These models and concepts have been reviewed recently and incorporated into a single model from a clinical perspective. ${ }^{55}$ This model will be discussed briefly at the end of the following section.

\section{GENETIC FACTORS}

All previous studies on monozygotic or bizygotic twins claim that dental development, including both the size and the shape of teeth, is governed principally by genetic processes, in which hundreds of genes take part. ${ }^{10,55,62,63}$ The evidence for genetic control is more significant in the etiology of hypodontia and the occurrence among individuals related to hypodontia patients is higher than in the general population. ${ }^{14,20,28,29,33,47,53,64,65}$ Many other studies have been done on genetic diseases. These studies have been classified in various ways according to the affected tooth structure (enamel vs dentin), by their specificity (syndromic vs nonsyndromic) and also by their pattern of inheritance: Autosomal dominant, autosomal recessive or X-linked recessive. ${ }^{65}$ There are numerous reports in the literature on the clinical genetics of tooth agenesis. Shimizu and Maeda have recently reviewed genetic studies which deal with hypodontia in human and mouse models. They report that nonsyndromic or familial hypodontia is more common than the syndromic type and that it might follow autosomal dominant, autosomal recessive or X-linked patterns of inheritance. ${ }^{33}$ 
Grahnen, in his family study in Sweden, reported that hypodontia is determined by genetic factors. ${ }^{47}$ However, among the subjects of Grahnen's study, the type of inheritance in the majority of cases of familial hypodontia seems to have been autosomal dominant. Furthermore, some types of hypodontia, such as peg-shaped upper lateral incisors, are claimed to be the result of modifying genes. ${ }^{47,66}$

Advances in the fields of molecular biology and human genetics have enlarged our understanding of tooth development, by exploring the important role played by homeobox genes in tooth formation and craniofacial development. ${ }^{33}$ Many researchers have found a direct relation between tooth formation and some of the regulatory homeobox genes: MAX1, PAX9 and AXIN2. ${ }^{14,20,23,28,33}$ MSX1 (muscle segment homeobox 1) is essential in mediating epithelial-mesenchymal interaction during tooth development and has been found to be associated with familial hypodontia and certain forms of syndromic hypodontia. ${ }^{23,28}$ MSX1 mutations predominantly affect second premolars and third molars. ${ }^{33}$ However, some other genetics studies have not found any correlation between MSX1 and premolar hypodontia. ${ }^{28,33}$ PAX9 (paired box gene 9) is also expressed in the prospective mesenchymal compartment of developing teeth. This gene has been identified in association with variable forms of hypodontia that affect the posterior region, particularly molar teeth. $^{20,64,67}$ The PAX9 gene has also been found to be associated with different forms of oligodontia. ${ }^{20}$ AXIN2 (axis inhibition protein-2) mutations are associated with hypodontia and involve a wider range of tooth types. ${ }^{23}$

Although previous studies have provided evidence for the role played by genetic factors in causing hypodontia, there is as yet no clear understanding of the genetics underlying this condition.

\section{ENVIRONMENTAL FACTORS}

Although, as discussed above, it appears that tooth agenesis is frequently caused by genetic factors, occasionally hypodontia can be associated with environmental factors. Major environmental factors such as infection of the tooth bud or trauma, ${ }^{68}$ or extraction of the preceding primary tooth, have been found to be associated with hypodontia owing to their effect on dental and organ development. Somatic diseases such as syphilis, scarlet fever and rickets are also associated with hypodontia, as are nutritional disturbances during pregnancy or infancy. Smoking during pregnancy, maternal medications, irradiation at an early age that may result in glandular and dental dysfunction are also implicated. ${ }^{14,69}$ Developing teeth are irreversibly affected by multiagent chemotherapy and radiation therapy.
However, the effect of irradiation has been found to be more severe than that of chemotherapeutic agents. ${ }^{70}$

\section{TOOTH AGENESIS MODELS}

Developmental defects in teeth have always been the subject of a great deal of interest on the part of researchers. Many studies have investigated and interpreted these defects using evolutionary and anatomic models such as Butler's field theory ${ }^{56}$ odontogenic polarity, Sofaer et al model of compensatory tooth size interactions, ${ }^{58}$ Osborn's clone concep $\mathrm{t}^{59}$ or the new discoveries in molecular biology which incorporate genetic factors. ${ }^{61}$ Many researchers have reviewed these theories and models and incorporated them into clinical research. ${ }^{14,55}$

\section{SYNDROMIC HYPODONTIA}

More than 120 syndromes listed in the Online Mendelian Inheritance in Man (OMIM) database are associated with tooth anomalies. ${ }^{18,71}$ The London dysmorphology database reported 150 syndromes as being associated with hypodontia. ${ }^{72}$ The absence of many teeth is commonly associated with specific syndromes or systematic abnormalities and is particularly related to ectodermal dysplasia. ${ }^{73}$ Nevertheless, hypodontia is a very common dental anomaly in patients with oral and facial clefts, Rieger syndrome, Down syndrome (trisomy 21), Witkop syndrome, van der Woude syndrome, Book syndrome, hemifacial microsomia and many others. ${ }^{27,28}$

In addition to inherited defects, tooth agenesis could occur as a result of somatic diseases such as syphilis, scarlet fever, rickets or nutritional disturbances during pregnancy or infancy which might affect tooth and other organ development. Also, glandular dysfunction could occur as a result of cranial irradiation in the very early stage of development and this can then lead to dental anomalies. ${ }^{14}$

\section{DENTAL ANOMALIES ASSOCIATED WITH HYPODONTIA}

Many dental characteristics have been reported to be associated with hypodontia, including microdontia, canine impaction, taurodontism, transposition and rotation of teeth and hypoplastic alveolar bone. ${ }^{6,10,16-18,74-76}$ Microdontia (reduction in tooth size) is considered one of the most common dental anomalies. It is common to see hypodontia of a maxillary lateral incisor on one side and a peg-shaped lateral incisor on the other side. ${ }^{16,18,37,40,77,78}$ It has been noted that even relatives of hypodontia patients usually have relatively reduced tooth size even if they do not have hypodontia. ${ }^{6,18}$ It has also been reported that hypodontia is 
associated with palatally impacted canines, ${ }^{74}$ and that there was a $26 \%$ increase in the transposition of the maxillary canine and first premolar in cases of maxillary lateral incisors agenesis. ${ }^{74}$ There is also a relationship between tooth rotation and hypodontia. Pirinen ${ }^{79}$ and Baccetti ${ }^{75}$ suggested that if there is a unilateral maxillary lateral incisor or premolar agenesis, it is more likely that the corresponding teeth on the other side will be rotated. Other researchers have found an increase of $10.8 \%$ in taurodontism of mandibular first molars associated with severe hypodontia. ${ }^{37,80,81}$

Goodman et $\mathrm{al}^{17}$ found that the failure of the alveolar bone to develop may create an increased freeway space in the range of 10 to $15 \mathrm{~mm}$. Furthermore, many researchers have reported delayed formation and eruption of permanent teeth, small teeth, ${ }^{82}$ ectopic eruption of first permanent molars, infraposition of primary molars, ${ }^{35,75,78}$ short root anomaly, invaginations in incisors, ${ }^{37,83}$ distoangulation of mandibular second premolars ${ }^{77}$ and palatally displaced canines. ${ }^{75,77,79}$

\section{SKELETAL PATTERN IN HYPODONTIA CASES}

There are not usually any noticeable changes to or effects on the skeletal pattern in the mild types of hypodontia, but it may be possible to see changes in cases of severe hypodontia. It has been reported that individuals with severe hypodontia or oligodontia associated with hypohidrotic ectodermal dysplasia had a flat or concave facial profile, obtuse nasolabial angle, retrognathic maxilla, reduced anterior face height and mandibular plane angle and reduced facial vertical height. ${ }^{84}$

\section{TOOTH SIZE AND SHAPE VARIATIONS IN HYPODONTIA}

Many studies in the dental literature have reported an association between hypodontia and microdontia of the remaining teeth. ${ }^{10,18,19,26,42,85-93}$ A reduction in tooth size was found in many members of the Hailuoto population in Finland, and this was found to be associated with hypodontia. ${ }^{86}$ Another group of researchers studied the tooth size discrepancy in the anterior region in 17,000 schoolchildren in Hawaii. They reported that when the maxillary lateral incisor was congenitally absent on one side, the adjacent central incisor was larger in size than its counterpart, suggesting a possible compensatory local interaction affecting the size of the adjacent tooth. ${ }^{58} \mathrm{~A}$ reduction in the tooth dimensions of relatives of patients with severe hypodontia has also been revealed. ${ }^{18}$ McKeown et $\mathrm{al}^{6}$ also found reduced tooth dimensions of some teeth in relatives of hypodontia patients. Furthermore, they compared the crown dimensions of hypodontia patients and their relatives on the one hand and those of a group of control subjects on the other. They found that both the hypodontia patients and their relatives had a smaller tooth size when compared to the control subjects. The degree of reduction in size was also found to be associated with the degree of severity of hypodontia. The closest group to the control group was the relatives of the hypodontia patients, while the group most affected by reduction in tooth size was the group of patients with severe hypodontia. ${ }^{19}$ Conversely, patients with supernumerary teeth have been shown to have increased tooth dimensions. ${ }^{94,95}$

Recent studies have also measured crown dimensions in hypodontia patients and have come to similar conclusions: That tooth size reduction is associated with hypodontia. Mirabella et al ${ }^{92}$ investigated the size differences (mesiodistal length only) between patients with congenitally missing lateral incisors; both types unilateral and bilateral agenesis. They found narrower teeth on their sample compared to those with no missing teeth, with the exception of the maxillary first molars. No differences were found in tooth size reduction between patients with unilateral or bilateral congenitally missing teeth. Yaqoob et al ${ }^{93}$ claim that the relationship between moderate or severe hypodontia and generalized microdontia is well established, but that there has been little research into the association between mild hypodontia and microdontia.

Shape alteration of the remaining teeth has been reported to be associated with hypodontia. ${ }^{46,58,61,86,87,91,96}$ Davies $^{46}$ reported the frequency of subjects with hypodontia and/or peg-shaping of one or more teeth as $22.2 \%$. A relationship between a peg-shaped upper lateral incisor on one side and the absence of the contralateral tooth was subsequently found. ${ }^{86}$ This finding suggested that hereditary genetics may play a weak role in the etiology of a missing tooth in hypodontia patients who have peg-shaped upper lateral incisors. Sofaer et $\mathrm{a}^{58}$ found that there is a higher prevalence of peg-shaped lateral incisors on the left than on the right side. This is also accompanied by smaller central incisors. It is more common to see the remaining teeth tending to be smaller when a peg-shaped lateral incisor tooth is present. ${ }^{91}$ Conical teeth or alterations in the shape of the remaining teeth were usually associated with the degree of severity of hypodontia. ${ }^{96}$

A direct relationship between alteration in tooth shape and the malformation that occurs within hypodontia has been reported in the dental literature. The deficiency of cusps in human teeth is also documented as being associated with hypodontia. It has been noticed that the palatal cusps of the posterior teeth-mainly the upper first premolar and upper first permanent molars-were usually affected and malformed 
(Foster and Van Roey, 1970). ${ }^{96}$ Lavelle ${ }^{87}$ also reported that $8 \%$ of his sample of hypodontia patients with third molars missing lacked the distolingual cusp of the first molar. Kondo and Townsend ${ }^{62}$ aimed to measure the areas of the four main cusps and the area of the Carabelli cusp, in addition to the crown dimensions. They found the first forming paracone displaying the least variation, and the last forming Carabelli cusp showing the greatest. The presence and absence of the Carabelli cusp has an effect on the shape of the molar teeth.

Different methods adopted to quantify tooth shape differences are described in the dental literature. ${ }^{19,97-99}$ Axelsson and Kirviskari ${ }^{97}$ used tooth shape ratio (crown indices) to describe the crown shape of members of different populations (North-East Iceland) using normal subjects. Another group of researchers used a modern imaging system to show the differences in tooth shape between hypodontia and control subjects. ${ }^{19}$ They found that tooth shape was different for teeth 12, 21, 22 and 32, with the crown taper from gingival margin to incisal edge increasing with the severity of the hypodontia. Agenter et $\mathrm{al}^{99}$ claimed that tooth shape could be evaluated indirectly following Peck and Peck's concept, ${ }^{100}$ which uses the $\mathrm{MD} / \mathrm{BL}$ ratio as an indicator of tooth shape. They claimed that the ratios are intercorrelated and that one dimension has an indirect effect on the other. Robinson et $\mathrm{al}^{98}$ studied tooth form applying the Procrustes technique in two dimension plane images following Brook et al. ${ }^{101}$ They reported shape differences between hypodontia and control subjects in the position of the incisal corners of the upper central incisors. The teeth of the hypodontia groups were more tapered in shape.

\section{CLINICAL IMPLICATIONS AND MANAGEMENT OF HYPODONTIA}

Hypodontia has significant clinical implications as it can seriously affect a person's physical and emotional status. The scenario is worse if the missing teeth are located in the anterior region for esthetic reasons. Furthermore, management of the condition is made difficult by problems of diagnosis, the severity of the tooth absence, and the general effect on the remaining teeth and dental occlusion. Although the severity of hypodontia varies among members of the same population, as mentioned above, it is still necessary to provide good care and treatment as these patients may be suffering from psychological problems.

The prime motivating factor for individuals seeking orthodontic treatment is esthetics. Some hypodontia patients seek treatment to manage depression caused by the deterioration in their appearance and/or functions. Hypodontia requires great care with extensive and complex treatments.
Unfortunately, there is no established formal procedure to manage patients with hypodontia. Their management may necessitate the help of many specialties. Treatment might range from single restorations to surgery and multiple restorations. ${ }^{102}$ Management will depend upon the pattern and severity of tooth absence, the amount of spaces present and, of course, the patient's attitude. The general principle in management is to deal with the space within the dental arches: i.e. a space closure in less severe cases, while prosthetic replacement as well as some orthodontic tooth movement: i.e., redistribution of space is usually the case in extensive conditions. Different options and methods of treatment have been suggested, including orthodontic movement and/or restorative replacements in the form of dentures, crowns, bridges, autotransplantation and dental implants, etc. Many factors should be evaluated before the commencement of management. These include the age of the candidate, the dental occlusion, soft tissue and skeletal patterns and the facial morphology of hypodontia, the number, color and morphology of the remaining teeth, the location of the absence, amount of alveolar ridge, oral hygiene, interest of the candidate, expectation of treatment, team/patient interaction and time as well as the cost of treatment. Furthermore, from an orthodontic perspective, variations in the size and shape of teeth with abnormal morphology are leading to incorrect bracket placement, since the standard prescription is still being used for hypodontia patients. The standard prescription will lead to different root angulation, inappropriate crown rotation and unequal torque between teeth. As mentioned previously, hypodontia not an easy condition to manage and treat. Many studies have shown the importance of the role of interdisciplinary teams in the management of hypodontia. ${ }^{8,102-106}$ A recent book by Hobkirk et $\mathrm{al}^{27}$ provides a comprehensive review for clinicians about the available options for the management of hypodontia adopting a multidisciplinary approach.

The clinical management of hypodontia requires careful multidisciplinary planning and has financial implications. A number of procedures can be carried out to cope with patients' wishes and which take into account their age. The cooperation between the different specialties in the team provides a wide variety of expertise which is not easy to find in one individual and the delivery of the treatment requires great care to meet the objectives of the treatment. ${ }^{27}$ At one of the international conferences on hypodontia an international agreement was announced about who should be on the team. The conclusion was that the members of the team should include the following: General dental practitioners, dental nurses, orthodontists, pediatric dentists, prosthodontists, oral and maxillofacial surgeons, specialist 
laboratory technicians, clinical psychologists, clinical geneticists, dermatologists, speech and language therapists. ${ }^{27}$ This is the ideal team, but in many situations it is possible to assemble such a team. Several papers have been published focusing on the importance and the role of the interdisciplinary team in the care of hypodontia patients both functionally and esthetically. ${ }^{104,107-109}$ This multidisciplinary approach is often costly but the benefits outweigh the cost. This approach maximizes the clinical outcomes for patients.

\section{CONCLUSION}

Hypodontia presents a complex problem to the dentists worldwide. It is evident that a significant amount of research has been done in this field and the classification, prevalence, etiology, associated anomalies, clinical implications and treatment options for hypodontia are well documented.

\section{REFERENCES}

1. Hunstadbraten K. Hypodontia in the permanent dentition. ASDC J Dent Child 1973;40:115-17.

2. Brook AH. Dental anomalies of number, form and size: Their prevalence in British schoolchildren. J Int Assoc Dent Child 1974;5:37-53.

3. Jorgenson RJ. Clinician's view of hypodontia. J Am Dent Assoc 1980;101:283-86.

4. Zhu JF, Marcushamer M, King DL, Henry RJ. Supernumerary and congenitally absent teeth: A literature review. J Clin Pediatr Dent 1996;20:87-95.

5. Dhanrajani PJ. Hypodontia: Etiology, clinical features and management. Quintessence Int 2002;33:294-302.

6. McKeown HF, Robinson DL, Elcock C, Al-Sharood M, Brook $\mathrm{AH}$. Tooth dimensions in hypodontia patients, their unaffected relatives and a control group measured by a new image analysis system. Eur J Orthod 2002;24:131-41.

7. Kirzioglu Z, Koseler Sentut T, Ozay Erturk MS, Karayilmaz H. Clinical features of hypodontia and associated dental anomalies: A retrospective study. Oral Dis 2005;11:399-404.

8. Wu CCL, Wong RWK, Hagg U. A review of hypodontia: The possible etiologies and orthodontic, surgical and restorative treatment options conventional and futuristic. Hong Kong Dent J 2007;4:113-21.

9. Swinnen S, Bailleul-Forestier I, Arte S, Nieminen P, Devriendt $\mathrm{K}$, Carels C. Investigating the etiology of multiple tooth agenesis in three sisters with severe oligodontia. Orthod Craniofac Res 2008;11:24-31.

10. Brook AH, Elcock C, Aggarwal M, Lath DL, Russell JM, Patel PI, et al. Tooth dimensions in hypodontia with a known PAX9 mutation. Arch Oral Biol 2009;54:S57-S62.

11. Brook AH, Griffin RC, Smith RN, Townsend GC, Kaur G, Davis GR, et al. Tooth size patterns in patients with hypodontia and supernumerary teeth. Arch Oral Biol 2009;54:S63-S70.

12. Pemberton TJ, Das P, Patel PI. Hypodontia: Genetics and future perspectives. Braz J Oral Sci 2005;4:695-706.

13. Hobkirk JA, Brook AH. The management of patients with severe hypodontia. J Oral Rehabil 1980;7:289-98.
14. Vastardis H. The genetics of human tooth agenesis: New discoveries for understanding dental anomalies. Am J Orthod Dentofacial Orthop 2000;117:650-56.

15. De Coster PJ, Marks LA, Martens LC, Huysseune A. Dental agenesis: Genetic and clinical perspectives. J Oral Pathol Med 2009;38:1-17.

16. Schalk-van der Weide Y, Steen WH, Bosman F. Distribution of missing teeth and tooth morphology in patients with oligodontia. ASDC J Dent Child 1992;59:133-40.

17. Goodman JR, Jones SP, Hobkirk JA, King PA. Hypodontia: 1. Clinical features and the management of mild to moderate hypodontia. Dent Update 1994;21:381-84.

18. Schalk-van der Weide Y, Bosman F. Tooth size in relatives of individuals with oligodontia. Arch Oral Biol 1996;41:469-72.

19. Brook AH, Elcock C, Al-Sharood MH, McKeown HF, Khalaf K, Smith RN. Further studies of a model for the etiology of anomalies of tooth number and size in humans. Connect Tissue Res 2002;43:289-95.

20. Mostowska A, Kobielak A, Biedziak B, Trzeciak WH. Novel mutation in the paired box sequence of PAX9 gene in a sporadic form of oligodontia. Eur J Oral Sci 2003;111:272-76.

21. Nunn JH, Carter NE, Gillgrass TJ, Hobson RS, Jepson NJ, Meechan JG, et al. The interdisciplinary management of hypodontia: Background and role of paediatric dentistry. Br Dent J 2003;194:245-51.

22. Polder BJ, Van't Hof MA, Van der Linden FPGM, KuijpersJagtman AM. A meta-analysis of the prevalence of dental agenesis of permanent teeth. Community Dent Oral Epidemiol 2004;32:217-26.

23. Cobourne MT. Familial human hypodontia-is it all in the genes? Br Dent J 2007; 203:203-08.

24. Burzynski NJ, Escobar VH. Classification and genetics of numeric anomalies of dentition. Birth Defects Orig Artic Ser 1983;19:95.

25. Vander Weide YS, Prahl-Andersen B, Bosman F. Tooth formation in patients with oligodontia. Angle Orthod 1993;63:31-37.

26. Brook AH. A unifying aetiological explanation for anomalies of human tooth number and size. Arch Oral Biol 1984;29: 373-78.

27. Hobkirk JA, Gill DS, Jones SP, Hemmings KW, Bassi GS, O’Donnell AL, et al. Hypodontia: A team approach to management (1st ed). Chichester: Wiley-Blackwell 2011.

28. Arte S, Nieminen P, Apajalahti S, Haavikko K, Thesleff I, Pirinen S. Characteristics of incisor-premolar hypodontia in families. J Dent Res 2001;80:1445-50.

29. Tan SPK, van Wijk AJ, Prahl-Andersen B. Severe hypodontia: Identifying patterns of human tooth agenesis. Eur J Orthod 2011;33:150.

30. Daugaard-Jensen J, Nodal M, Skovgaard LT, Kjær I. Comparison of the pattern of agenesis in the primary and permanent dentitions in a population characterized by agenesis in the primary dentition. Int J Paediatr Dent 1997;7:143-48.

31. Salama FS, Abdel-Megid FY. Hypodontia of primary and permanent teeth in a sample of Saudi children. Egypt Dent J 1994;40:625-32.

32. Larmour CJ, Mossey PA, Thind BS, Forgie AH, Stirrups DR. Hypodontia — a retrospective review of prevalence and etiology. Part I. Quintessence Int 2005;36:263-70.

33. Shimizu T, Maeda T. Prevalence and genetic basis of tooth agenesis. Jpn Dent Sci Rev 2009;45:52-58. 
34. Sofaer JA. Genetic variation and tooth development. Br Med Bull 1975;31:107-10.

35. Bjerklin K, Al-Najjar M, Karestedt H, Andren A. Agenesis of mandibular second premolars with retained primary molars: A longitudinal radiographic study of 99 subjects from 12 years of age to adulthood. Eur J Orthod 2008;30:254-61.

36. Harris EF, Clark LL. Hypodontia: An epidemiologic study of American black and white people. Am J Orthod Dentofacial Orthop 2008;134:761-67.

37. Gupta SK, Saxena P, Jain S, Jain D. Prevalence and distribution of selected developmental dental anomalies in an Indian population. J Oral Sci 2011;53:231-38.

38. Celikoglu M, Kazanci F, Miloglu O, Oztek O, Kamak H, Ceylan I. Frequency and characteristics of tooth agenesis among an orthodontic patient population. Med Oral Patol Oral Cir Bucal 2010;15:e797-801.

39. Gomes RR, Da Fonseca JAC, Paula LM, Faber J, Acevedo AC. Prevalence of hypodontia in orthodontic patients in Brasilia, Brazil. Eur J Orthod 2010;32:302.

40. Kositbowornchai S. Prevalence and distribution of dental anomalies in pretreatment orthodontic Thai patients. Khon Kaen Univ Dent J 2011;13:92-100.

41. Mattheeuws N, Dermaut L, Martens G. Has hypodontia increased in Caucasians during the 20th century? A metaanalysis. Eur J Orthod 2004;26:99-103.

42. Harris EF, Evans JB, Smith AS. Bilateral asymmetry of tooth formation is elevated in children with simple hypodontia. Arch Oral Biol 2011;56:687-94.

43. Hashem AA, O’Connell B, Nunn J, O’Connell A, Garvey T, O'Sullivan M. Tooth agenesis in patients referred to an Irish tertiary care clinic for the developmental dental disorders. J Ir Dent Assoc 2009;56:23-27.

44. Lynham A. Panoramic radiographic survey of hypodontia in Australian Defence Force recruits. Aust Dent J 1990;35:19-22.

45. Yamada H, Kondo S, Hanamura H, Townsend GC. Tooth size in individuals with congenitally missing teeth: A study of Japanese males. Anthropol Sci 2010;100:87-93.

46. Davis PJ. Hypodontia and hyperdontia of permanent teeth in Hong Kong school children. Community Dent Oral Epidemiol 1987;15:218-20.

47. Grahnen H. Hypodontia in the permanent dentition. A clinical and genetic investigation. Odontol Revy 1956;7:1-100.

48. Bassett JL. Replacement of missing mandibular lateral incisors with a single pontic all-ceramic prosthesis: A case report. Prac Periodont Aesthet Dent 1997;9:455.

49. Bishara SE. Third molars: A dilemma! Or is it? Am J Orthod Dentofacial Orthop 1999;115:628-33.

50. Bailit HL. Dental variation among populations. An anthropologic view. Dent Clin North Am 1975;19:125-39.

51. Van Wijk AJ, Tan SPK. A numeric code for identifying patterns of human tooth agenesis: A new approach. Eur J Oral Sci 2006;114:97-101.

52. Rushmah M. Hypodontia of the primary and permanent dentition. J Clin Pediatr Dent 1992;16:121-23.

53. Stockton DW, Das P, Goldenberg M, D’Souza RN, Patel PI. Mutation of PAX9 is associated with oligodontia. Nat Genet 2000;24:18-19.

54. Parkin N, Elcock C, Smith RN, Griffin RC, Brook AH. The aetiology of hypodontia: The prevalence, severity and location of hypodontia within families. Arch Oral Biol 2009; 54:S52S56.
55. Townsend G, Hughes T, Luciano M, Bockmann M, Brook A. Genetic and environmental influences on human dental variation: A critical evaluation of studies involving twins. Arch Oral Biol 2009;54:S45-S51.

56. Butler PM. Studies of the mammalian dentition-differentiation of the post canine dentition. Proc Zool Soc Lond B 1939; 109:1-36.

57. Dahlberg AA. The changing dentition of man. J Am Dent Assoc 1945;32:676-90.

58. Sofaer JA, Chung CS, Niswander JD, Runck DW. Developmental interaction, size and agenesis among permanent maxillary incisors. Hum Biol 1971;43:36-45.

59. Osborn JW. Morphogenetic gradients: Fields versus clones. Development, function and evolution of teeth. London: Academic Press 1978:171-201.

60. Sharpe PT. Homeobox genes and orofacial development. Connect Tissue Res 1995; 32:17-25.

61. Mitsiadis TA, Smith MM. How do genes make teeth to order through development? J Exp Zoolog B Mol Dev Evol 2006;306:177-82.

62. Kondo S, Townsend GC. Associations between Carabelli trait and cusp areas in human permanent maxillary first molars. Am J Phys Anthropol 2006;129:196-203.

63. Townsend G, Alvesalo L, Brook A. Variation in the human dentition: Some past advances and future opportunities. J Dent Res 2008;87:802-05.

64. Tallon-Walton V, Manzanares-Cespedes MC, Arte S, CarvalhoLobato P, Valdivia-Gandur I, Garcia-Susperregui A, et al. Identification of a novel mutation in the PAX9 gene in a family affected by oligodontia and other dental anomalies. Eur J Oral Sci 2007;115:427-32.

65. Bailleul-Forestier I, Molla M, Verloes A, Berdal A. The genetic basis of inherited anomalies of the teeth. Part 1: Clinical and molecular aspects of nonsyndromic dental disorders. Eur J Med Genet 2008;51:273-91.

66. Alvesalo L, Portin P. The inheritance pattern of missing, PEGshaped, and strongly mesiodistally reduced upper lateral incisors. Acta Odontol Scand 1969;27:563-75.

67. Thesleff I. Genetic basis of tooth development and dental defects. Acta Odontol Scand 2000;58:191-94.

68. Gullikson JS. Tooth morphology in rubella syndrome children. ASDC J Dent Child 1975;42:479-82.

69. Graber LW. Congenital absence of teeth: A review with emphasis on inheritance patterns. J Am Dent Assoc 1978;96: 266-75.

70. Näsman M, Forsberg CM, Dahllöf G. Long-term dental development in children after treatment for malignant disease. Eur J Orthodont 1997;19:151-59.

71. McKusick V. Mendelian inheritance in man and its online version, OMIM. Am J Hum Genet 2007;80:588-604.

72. Winter RM, Baraitser M. London dysmorphology database version 3.0, Dysmorphology photolibrary on CD-Rom version 3.0. Oxford, Oxford University Press. 2001.

73. Goodman RM, Gorlin RJ. The face in genetic disorders. Saint Louis: Mosby 1970.

74. Peck S, Peck L, Kataja M. Site-specificity of tooth agenesis in subjects with maxillary canine malpositions. Angle Orthod 1996;66:473-76.

75. Baccetti T. Tooth rotation associated with aplasia of nonadjacent teeth. Angle Orthod 1998;68:471-74.

76. Peck S, Peck L, Kataja M. Concomitant occurrence of canine malposition and tooth agenesis: Evidence of orofacial genetic fields. Am J Orthod Dentofacial Orthop 2002;122:657-60. 
77. Garib DG, Peck S, Gomes SC. Increased occurrence of dental anomalies associated with second-premolar agenesis. Angle Orthod 2009;79:436-41.

78. Garib DG, Alencar BM, Lauris JRP, Baccetti T. Agenesis of maxillary lateral incisors and associated dental anomalies. Am J Orthod Dentofacial Orthop 2010;137:731-32.

79. Pirinen S, Arte S, Apajalahti S. Palatal displacement of canine is genetic and related to congenital absence of teeth. J Dent Res 1996;75:1742-46.

80. Lai PY, Seow WK. A controlled study of the association of various dental anomalies with hypodontia of permanent teeth. Pediatr Dent 1989;11:291-96.

81. Schalk-Van Der Weide Y, Steen WHA, Bosman F. Taurodontism and length of teeth in patients with oligodontia. J Oral Rehabil 1993;20:401-12.

82. Garn SM, Lewis AB. The gradient and the pattern of crownsize reduction in simple hypodontia. Angle Orthod 1970;40: 51-58.

83. Apajalahti S, Arte S, Pirinen S. Short root anomaly in families and its association with other dental anomalies. Eur J Oral Sci 1999;107:97-101.

84. Bondarets N, McDonald F. Analysis of the vertical facial form in patients with severe hypodontia. Am J Phys Anthropol 2000;111:177-84.

85. Rantanen AV. On the frequency of the missing and pegshaped maxillary lateral incisor among Finnish students. Am J Phys Anthropol 1956;14:491-96.

86. Brook AH. Multilevel complex interactions between genetic, epigenetic and environmental factors in the aetiology of anomalies of dental development. Arch Oral Biol 2009;54: S3-S17.

87. Lavelle CLB. Analysis of attrition in adult human molars. J Dent Res 1970;49:822-28.

88. Baum BJ, Cohen MM. Agenesis and tooth size in the permanent dentition. Angle Orthod 1971;41:100.

89. Rune B, Sarnas KV. Tooth size and tooth formation in children with advanced hypodontia. Angle Orthod 1974;44:316-21.

90. Harris EF, Bailit HL. A principal components analysis of human odontometrics. Am J Phys Anthropol 1988;75:87-99.

91. Ooshima T, Sugiyama K, Sobue S. Oligodontia in the primary dentition with permanent successors: Report of case. ASDC J Dent Child 1988;55:75-77.

92. Mirabella AD, Kokich VG, Rosa M. Analysis of crown widths in subjects with congenitally missing maxillary lateral incisors. Eur J Orthod 2012;34:783-87.

93. Yaqoob O, DiBiase AT, Garvey T, Fleming PS. Relationship between bilateral congenital absence of maxillary lateral incisors and anterior tooth width. Am J Orthod Dentofacial Orthop 2011;139:e229-e233.

94. Khalaf K, Robinson DL, Elcock C, Smith RN, Brook AH. Tooth size in patients with supernumerary teeth and a control group measured by image analysis system. Arch Oral Biol 2005;50:243-48.

95. Khalaf K, Smith RN, Elcock C, Brook AH. Multiple crown size variables of the upper incisors in patients with supernumerary teeth compared with controls. Arch Oral Biol 2009;54:S71-S78.
96. Foster TD, Van Roey OR. The form of the dentition in partial anodontia. Dental Pract Dent Rec 1970;20:163.

97. Axelsson G, Kirveskari P. Crown size of permanent teeth in Icelanders. Acta Odontol Scand 1983;41:181-86.

98. Robinson DL, Blackwell PG, Stillman EC, Brook AH. Planar Procrustes analysis of tooth shape. Arch Oral Biol 2001;46: 191-99.

99. Agenter MK, Harris EF, Blair RN. Influence of tooth crown size on malocclusion. Am J Orthod Dentofacial Orthop 2009;136:795-804.

100. Peck S, Peck H. Othodontic aspects of dental anthropology. Angle Orthod 1975;45:95.

101. Brook AH, Smith RN, Elcock C, Al-Sharood MH, Shah AA, Karmo M. The measurement of tooth morphology: Development and validation of a new image analysis system. Dental morphology.Oulu, Finland: Oulu University Press 1998: 380-87.

102. Valle AL, Lorenzoni FC, Martins LM, Valle CVM, Henriques JFC, Almeida ALPF, et al. A multidisciplinary approach for the management of hypodontia: Case report. J Appl Oral Sci 2011;19:544-48.

103. Carter NE, Gillgrass TJ, Hobson RS, Jepson N, Eechan JGM, Nohl FS, et al. The interdisciplinary management of hypodontia: Orthodontics. Br Dent J 2003;194:361-66.

104. McNamara C, Foley T, McNamara CM. Multidisplinary management of hypodontia in adolescents: Case report. J Can Dent Assoc 2006;72:740-46.

105. Brough E, Donaldson AN, Naini FB. Editor's comment and Q\&A: Canine substitution for missing maxillary lateral incisors: The influence of canine morphology, size, and shade on perceptions of smile attractiveness. Am J Orthod Dentofacial Orthop 2010;138:705-07.

106. Al-Anezi SA. Orthodontic treatment for a patient with hypodontia involving the maxillary lateral incisors. Am J Orthod Dentofacial Orthop 2011;139:690-97.

107. Jepson NJ, Nohl FS, Carter NE, Gillgrass TJ, Meechan JG, Hobson RS, et al. The interdisciplinary management of hypodontia: Restorative dentistry. Br Dent J 2003;194:299-304.

108. Simeone P, De Paoli C, De Paoli S, Leofreddi G, Sgro S. Interdisciplinary treatment planning for single-tooth restorations in the esthetic zone. J Esthet Restor Dent 2007;19:79-89.

109. Worsaae N, Jensen BN, Holm B, Holsko J. Treatment of severe hypodontia-oligodontia—an interdisciplinary concept. Int J Oral Maxillofac Surg 2007;36:473-80.

\section{ABOUT THE AUTHORS}

\section{Ibrahim AIShahrani (Corresponding Author)}

Assistant Professor, Department of Preventive Dental Sciences, King Khalid University College of Dentistry, Abha 61471, PO Box 3263, Saudi Arabia, Phone: +966-7-2419293, e-mail: ishahrani@kku.edu.sa

\section{Rafi A Togoo}

Associate Professor, Department of Preventive Dental Sciences, King Khalid University College of Dentistry, Abha, Saudi Arabia

\section{Mohammed Ali AIQarni}

Assistant Professor, Department of Restorative Dental Sciences, King Khalid University College of Dentistry, Abha, Saudi Arabia 